\title{
Endocarditis secondary to Streptococcus salivarius: case report
}

\author{
Endocarditis por Streptococcus salivarius: caso clínico
}

Edwar J. Rozo-Ortiz', Ledmar J. Vargas-Rodríguez², Sara M. Martínez-Bautista ${ }^{3}$, and

Paola A. Bolívar-Córdoba²

${ }^{1}$ Department of Internal Medicine, Hospital San Rafael; ${ }^{2}$ Epidemiology Department; ${ }^{3}$ Faculty of Medicine. Universidad de Boyacá, Tunja, Colombia

Streptococcus salivarius is a bacterium with spherical morphology and gram-positive characteristics, which groups into pairs or short chains. This microorganism belongs to the Streptococcus viridans family, and it is therefore regarded as a facultative anaerobe. Rarely does it behave as a pathogen 1 .

The case of a 34-year-old woman from the city of Tunja (Colombia) without relevant previous medical history is presented. She attended for a clinical condition that had been ongoing for one month that consisted of non-quantified fever peaks accompanied by asthenia, adynamia, myalgia, arthralgia, paresthesia on extremities, nocturnal diaphoresis and holocranial headache.

On physical examination she was found with tachycardia, febrile $\left(38.1^{\circ} \mathrm{C}\right)$, alert, oriented, with signs of gingivitis and dental caries, with findings of gallop in heart sounds and grade II diastolic heart murmur on aortic area. The rest of the examination was within normal parameters. Admission tests showed leukocytosis with predominance of neutrophils, high erythrocyte sedimentation rate, increased transaminases, mild hypokalemia, arterial blood gases with simple respiratory alkalosis, without hyperlactatemia. Blood culture reported the presence of $S$. salivarius.

Transesophageal echocardiogram showed a bicuspid aortic valve with moderate insufficiency and negative study for vegetation. However, was a patient diagnosis considered likely to be infectious endocarditis due to the presence of one major criterion and three minor criteria on the Duke scale.

The patient had subacute endocarditis caused by $S$. salivarius, and thus she was managed with ceftriaxone at a dose of $2 \mathrm{~g} / 24 \mathrm{~h}$ intravenously for 28 days, with an adequate evolution being achieved.

$S$. salivarius behaves like a hemolytic microorganism, grows in blood agar cultures and is present in the oral cavity, generally on the back of the tongue, and on pharyngeal mucosa and upper and lower respiratory tract ${ }^{1,2}$. This bacterium had been traditionally regarded as a non-virulent microorganism, and its isolation in blood cultures was attributed to contamination, since it can be transiently found. This had made for it to be considered an opportunistic micro-organism, since it mainly affects people in immunosuppressed states, such as neutropenic cancer patients and cirrhotic subjects, among others ${ }^{3,4}$. The patient of the presented case had a predisposition for developing native valvular endocarditis, given her bicuspid aortic valve and poor oral hygiene ${ }^{5}$.

Among the pathologies $S$. salivarius can cause, cases of caries have been reported, septicemia in neutropenic patients ${ }^{4}$, as well as some isolated cases of meningitis, brain abscess ${ }^{2}$, endophthalmitis, endocarditis, pneumonia and osteomyelitis ${ }^{6}$. S. salivarius has

\section{Correspondence:}

*Ledmar J. Vargas-Rodríguez

E-mail: lejovaro@gmail.com DOI: 10.24875/ACME.M21000233
Date of reception: 10-03-2020

Date of acceptance: 07-07-2020 license (http://creativecommons.org/licenses/by-nc-nd/4.0/).

Available online: $20-10-2021$ Arch Cardiol Mex (Eng). 2021;91(3):349-350 www.archivoscardiologia.com 
been found to affect immune responses by inhibiting inflammatory pathways, which suggests a role in human epithelial cells immune response modulation, and similarly to Streptococcus pyogenes colonization, it affects the secretion of interleukin 8 and the innate immune response pathways in bronchial and pharyngeal epithelial cells, which suggests a role in human nasopharyngeal immune responses ${ }^{6,7}$.

Blood culture has a sensitivity of $5 \%(0.13-24.87 \%)$, but a positive predictive value of $100 \%$, which shows that a positive result confirms the presence of the microorganism in blood and mandates for immediate therapeutic measures to be taken in order to obtain the best results for patients ${ }^{8}$; however, studies agree in mentioning that sensitivity is higher by using the polymerase chain reaction to identify these microorganisms in heart valves ${ }^{9}$.

Management of this microorganism includes some therapeutic options, among which beta-lactam antimicrobials are considered to be the first line of treatment ${ }^{2}$, followed by antibiotics accompanied by beta-lactamase inhibitors, vancomycin and gentamicin, among others ${ }^{10}$. It is important bearing in mind that endocarditis can generate some complications distant from the heart, including neurological pathologies such as ischemic accidents and brain abscesses ${ }^{2}$.

It should be borne in mind that this pathogen mainly affects people with any immunodeficiency, and hence the interest regarding this case, since it involves an immunocompetent person with dental status deterioration, which shows that, by being present in usual flora, this pathogen can infect patients either for their clinical condition or even by simple dental management, thus confirming the pathogenic role of the microorganism.

\section{Funding}

The present investigation has not received any specific grant from agencies of the public, commercial or non-profit sectors.

\section{Conflicts of interest}

None.

\section{Ethical disclosures}

Protection of human and animal subjects. The authors declare that no experiments have been performed on humans or animals for this investigation.

Confidentiality of data. The authors declare that no patient data appear in this article.

Right to privacy and informed consent. The authors declare that no patient data appear in this article.

\section{References}

1. Blanco L. Streptococcus salivarius: características, morfología, cultivo. Lifeder. (Consultado el 29 de febrero de 2020.) Disponible en: https:// www.lifeder.com/streptococcus-salivarius/

2. Knudtzen FC, Lynge M, Gaini S. Pontine abscess with initial treatment failure following infectious endocarditis with Streptococcus salivarius. BMJ Case Rep. 2015;2015:bcr2014205949.

3. Avci S, Canpolat U, Kalayci S, Gül M, Çağli K. Nightmare of a breastfeeding mother: aortic valve endocarditis due to Streptococcus salivarius after breast engorgement. West Indian Med J. 2014;63:389-90.

4. Campos Franco J, López Rodríguez R, Alende Sixto R, González Quintela A. Bacteriemia y celulitis por Streptococcus salivarius en un paciente cirrótico. Gastroenterol Hepatol. 2012;35:105-6.

5. Felix L, Gurunathan R. I can't believe it's not bovis: a case of Streptococcus salivarius related endocarditis. J Hosp Med. 2014;9(Suppl 2): abstr. 412. Disponible en: https://www.shmabstracts.com/abstract/ i-cant-believe-its-not-bovis-a-case-of-streptococcus-salivarius-related-endocarditis/. Accessed March 30, 2020

6. Kaci G, Goudercourt D, Dennin V, Pot B, Doré J, Ehrlich SD, et al. Anti-inflammatory properties of Streptococcus salivarius, a commensal bacterium of the oral cavity and digestive tract. Appl Environ Microbiol. 2014;80:928-34.

7. Elsawy AM, Faidah HS, Redwan EM. Streptococcus salivarius meningitis in immunocompetent: a case report. Int Arch Med Microbiol. 2018;1:004.

8. Faraji R, Behjati-Ardakani M, Faraji N, Moshtaghiounc SM, Kalantard SM, Pedarzade A, et al. Molecular diagnosis of bacterial definite infective endocarditis by real-time polymerase chain reaction. Cardiol Res. 2018;9:99-106.

9. Kim SL, Gordon SM, Shrestha NK. Distribution of streptococcal groups causing infective endocarditis: a descriptive study. Diagn Microbiol Infect Dis. 2018;91:269-72.

10. De Troia A, Mottini F, Biasi L, Azzarone M, Tecchio T, Salcuni PF. Superior mesenteric artery aneurysm caused by aortic valve endocarditis: the case report and review of the literature. Vasc Endovasc Surg. 2016;50:88-93. 